\title{
DFT-Comparison of Anti-Cancer Effect of Ibuprofen Drug Anions and Breast Cancer Treatment by Ethanolic Solution of Nitrobenzaldehyde in Two Hours
}

\author{
Anwar El-Shahawy \\ Chemistry Department, Faculty of Science, Assiut University, Assiut, Egypt \\ Email: anwarshahawy@gmail.com
}

How to cite this paper: El-Shahawy, A. (2017) DFT-Comparison of Anti-Cancer Effect of Ibuprofen Drug Anions and Breast Cancer Treatment by Ethanolic Solution of Nitrobenzaldehyde in Two Hours. Computational Chemistry, 5, 9-21. http://dx.doi.org/10.4236/cc.2017.51002

Received: October 1, 2016

Accepted: December 12, 2016

Published: December 15, 2016

Copyright $\odot 2017$ by author and Scientific Research Publishing Inc. This work is licensed under the Creative Commons Attribution International License (CC BY 4.0).

http://creativecommons.org/licenses/by/4.0/ (c) (i) Open Access

\begin{abstract}
Focusing our DFT calculations on the carboxylic acid drugs such as ibuprofen drug (IBF), it has been concluded that the anions of these types of drugs have the spontaneous electron donor character to all the carcinogenic cells of electron deficiency in their nuclei. Due to the spontaneity of electron transfer of anions, it has been found clinically that ibuprofen drug cures cancers of colon, protostate, lung and breast. The breast cancer treatment of Matthew Gdovin group in two hours by injection of ethanolic solution of nitrobenzaldehyde in the breast tumor in presence of uv-irradiation has been studied from TD-DFT point of view; the excited states of these molecules in presence of uv-irradiation act as electron donors to the cancerous cells to compensate the electron deficiency. Finally, it has been concluded that the electron transfer is the main cause of the breast cancer treatment which is the most aggressive type of cancers and is one of the hardest to treat.
\end{abstract}

\section{Keywords}

DFT/6-31G**, TD-DFT, IBF, Anions, Ethanol, Nitrobenzaldehyde, UV

\section{Introduction}

Cancer is a principle cause of death in both more and less in economically developed countries due to tobacco use, obesity, physical inactivity, and infections, [1]. ibuprofen drug is one of the classes of drugs known as non-steroidal anti-inflammatory drugs (NSAIDS), with moderate anti-inflammatory, analgesic, and antipyretic activity. Recently, the regular use of ibuprofen prevents from some certain cancers including prostate, colon, breast, lung, and gastric cancers due to the inhibition of cyclooxygenase-2(COX-2), [2] [3]. Ibuprofen reduces risk of human lung cancer by selective cyc- 
looxygenase 2 (Cox-2), [4]. The 2-arylpropanoic acids (2-APAs) are a group of nonsteroidal anti-inflammatory drugs, the majority of which have been remarked as racemic mixtures because they have asymmetric carbon atom. These drugs exhibit stereoselectivity in both their pharmacological activity, i.e. inhibition of cyclo-oxygenase, [5]. Naveen et al. have reported that the S-isomer of IBF is biologically active than R-isomer and the racemic mixture of the two isomers is active than R-isomer [6].

Breast cancer is the second most common cancer over worldwide after lung cancer, the fifth most common cause of cancer death in women. Triple-negative breast cancer tumors relapse more frequently in spite of good initial response to chemotherapy, and have a worse prognosis than hormone receptor-positive, luminal subtypes. New systemic therapies are urgently needed because hormonal therapies and HER2-targeted agents are ineffective in this group of tumors. Poly (ADP-ribose) polymerase inhibitors, angiogenesis inhibitors, EGFR-targeted agents, and src kinase and mTOR inhibitors are among the therapeutic agents being actively investigated in clinical trials in these patients [7]. Circulating tumor cells (CTCs) have a crucial role in the metastatic cascade, tumor dissemination and progression. Furthermore, CTCs are involved in treatment failure, therapy resistance and disease progression. New therapeutic possibilities are offered by the established clinical prognostic and predictive value of CTCs with the additional possibility of using them for the real-time monitoring of systemic-therapy efficacy. This review discusses the future of clinical applications of CTCs in breast cancer including the incorporation of CTCs as end points in clinical trials and the blockade of tumor dissemination and self seeding via the therapeutic targeting of CTCs [8]. Genetic testing for breast cancer susceptibility is widely available in North America and in Europe. The optimum treatment of women with breast (or ovarian) cancer and a BRCA1 or BRCA2 mutation may be different from that of non-carriers. Thus, identifying the BRCA mutation status in patients can assist appropriate decision making for individualized cancer prevention, screening and treatment [9]. Synthetic lethality has emerged as a novel approach to treat cancer. Inhibitors of poly (ADP-ribose) polymerase, a target that has synthetic lethality with BRCA mutations, have already shown promise in clinical trials. The authors of this review described the clinical application of synthetic lethality for patients with breast cancer, and discussed biomarkers that could be used to select patients who will respond to this therapy. Other potential genes that can be involved in synthetic lethality, and are thus new targets, have been also explored [10]. Ethanol is metabolized in human to acetaldehyde by alcohol dehydrogenase (ADH) enzyme. The enzyme responsible for oxidation of acetaldehyde is aldehyde dehydrogenase (ALDH). Both formation and degradation of acetaldehyde depends on the activity of these enzymes. The total alcohol dehydrogenase enzyme is significantly higher in cancer tissues than in these healthy organs (e.g. liver, stomach, esophagus, colorectum). Moreover the activity of $\mathrm{ADH}$ is much higher than the activity of ALDH producing high acidity inside the cancerous degradation cells [11]. Efforts to destroy cancer cells without harming surrounding tissue, using beams of light to activate chemicals or particles in breast tumors have shown much promise. This can be called photodynamic therapy, most of the current methods of using it to involve creating a particular deadly form of oxygen or heating up particles or chemicals in tumors. Now, a researcher Mat- 
thew Gdovin has found a way to use the therapy to alter the $\mathrm{pH}$ of tumors so that they commit suicide without harming the rest of the body [12].

\section{Method of Calculations}

\subsection{DFT Calculations}

Computational studies on the isolated molecules in the gas phase were performed by the aid of GAUSSIAN 03 package. Minimum energy structure was achieved using semiempirical AM1 method. DFT/6-31 ${ }^{\star \star} \mathrm{G}$ calculations were performed on the minimum energy structures using the closed shell Hartree-Fock, Becke's three parameters density functional theory, DFT, [13] [14] in combination with the Lee, Yang and Parr correlation functional B3LYP. The differentiation between the conformers' $\mathrm{R}$ and $\mathrm{S}$ of the ibuprofen drug has been based on the total energy difference which can be calculated via SCF using RHF for these types of molecules and UHF for the molecular anions. The excited states of nitrobenzene derivatives in ethanol have been studied by TD-DFT method.

With respect to DFT calculations, it can be carried out using the basis set B3LYP/ $6-31^{* *} \mathrm{G}$ and the energy of the DFT theory can be represented as a function of the electron density as follows:

$$
\begin{aligned}
E|\rho|= & \frac{-\hbar^{2}}{2 m_{e}} \sum_{i=1}^{n} \int \psi_{i}^{*}\left(r_{1}\right) \nabla^{2} \psi_{i}\left(r_{1}\right) \mathrm{d} r_{1}-\sum_{i=1}^{n} \int \frac{z_{r} e^{2}}{4 \pi \varepsilon_{o} r_{11}} \rho\left(r_{1}\right) \mathrm{d} r_{1} \\
& +\frac{1}{2} \int \frac{\rho\left(r_{1}\right) \rho\left(r_{2}\right) e^{2}}{4 \pi \varepsilon_{0} r_{12}} \mathrm{~d} r_{1} \mathrm{~d} r_{2}+E_{x c}|\rho| \quad \text { where } \hbar=\frac{h}{2 \pi}
\end{aligned}
$$

where $\rho$ is the electron density

$$
\rho=\sum_{i=1}^{\text {HOMO }}\left|\psi_{i(r)}\right|^{2}=\sum_{i=1}^{H O M O} C_{i(r)}^{2}
$$

where $C_{i}$ is the eigenvectors for each molecular orbital eigenfunction $\psi_{i}$ and

$$
\hat{H}_{i}=\frac{-\hbar^{2}}{2 m_{e}} \nabla_{i}^{2}-\sum_{i}^{n} \frac{z_{1} e^{2}}{4 \pi \varepsilon_{0} r_{12}}+\int \frac{\rho\left(r_{2}\right) e^{2}}{4 \pi \varepsilon_{0} r_{12}}+V_{x c}\left(r_{1}\right)
$$

where $\hat{H}_{i}$ is the total energy Hamiltonian operator. $\varepsilon$ is the permittivity of the vacuum.

\subsection{Electron Transfer Studies}

The electron transfer energy $\left(E_{C T}\right)$ in the CT-complex between the donor and the acceptor (cation and anion) was calculated according to the following equation [13].

$$
E_{C T}=I_{D}-E_{A}-\left(C^{+}+C^{-}\right)
$$

where $I_{D}$ is the ionization potential of the donor and $E_{A}$ is the electron affinity of the acceptor. $C^{+}$is the columbic potential energy of the donor as a cation, and $C^{-}$is the columbic potential energy of the acceptor as an anion. The columbic potential energy can be calculated, according to the following equation [13].

$$
C=14.4 \sum_{i=1}^{N} \sum_{j \neq i}^{N} Z_{i} Z_{j} / r_{i j}(\mathrm{eV})
$$

where $Z_{i}$ and $Z_{j}$ are the charge densities of two different atoms in a molecule and $r_{i j}$ is 
the distance between two atoms in a molecule of $\mathrm{N}$ atoms in angstrom. The electron transfer-band position in $\mathrm{nm}$ can be obtained by dividing 1240.824 by the electron transfer energy in electron volts i.e. $(E \lambda=1240.824 \mathrm{eV} \mathrm{nm})$.

\section{Results and Discussion}

\subsection{Anticancer Effect of Ibuprofen Drug}

Ibuprofen (IBF), 2(4-isobutylphenyl) propanoic acid, acts as a non-steroidal anti-inflammatory drug (NSAID) which always used for relieving pain, antipyretic and anti-inflammatory. About $60 \%$ of patients improved by any given NSAID and it is advised that if one does not work that another can be used. Ibuprofen may be considered as weak anti-inflammatory than other NSAIDs. Ibuprofen has a particularly interesting property, and it can exist as a pair of optical isomers that are mirror images of each other. IBF molecules have two conformers $\mathrm{R}$ and $\mathrm{S}$ as shown in Figure 1. These mirror images are non-super-imposable, which are mirror images but not identical. The presence of asymmetric carbon atom in IBF molecules induces optical activity. The two optical isomers of ibuprofen are identified by the prefixes $\mathrm{R}^{-}$(Levo Rotatory) and $\mathrm{S}^{+}$ (Dextro Rotatory) i.e. change the orientation of the polarized light. DFT calculations have been performed according to El-Shahawy, [13] [14] using the basis set $6-31^{\star \star} \mathrm{G}$ (Figure 1, Table 1).

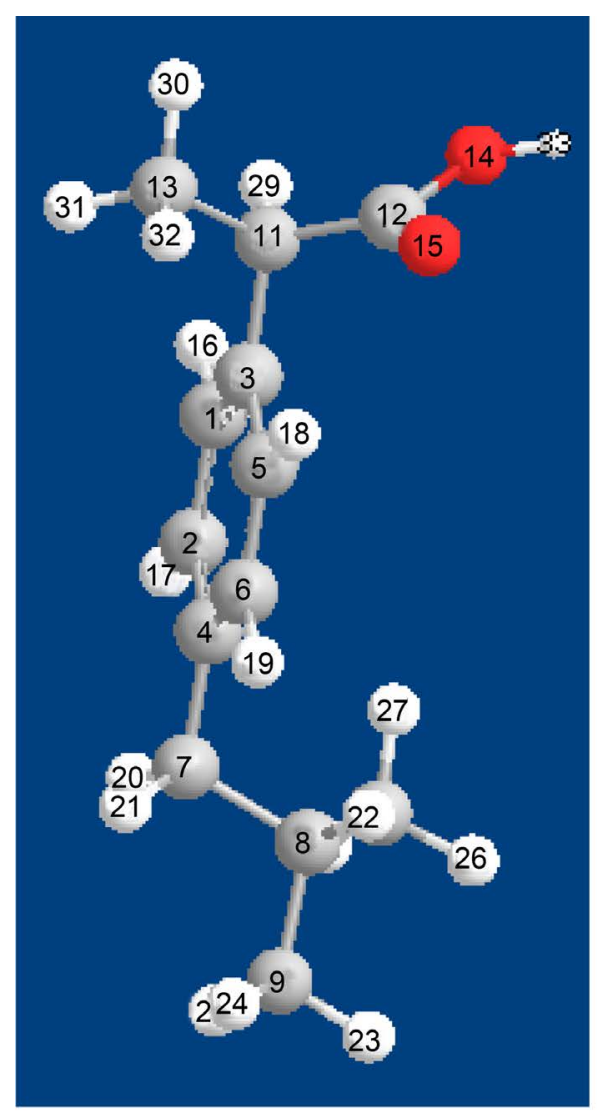

R-FORM

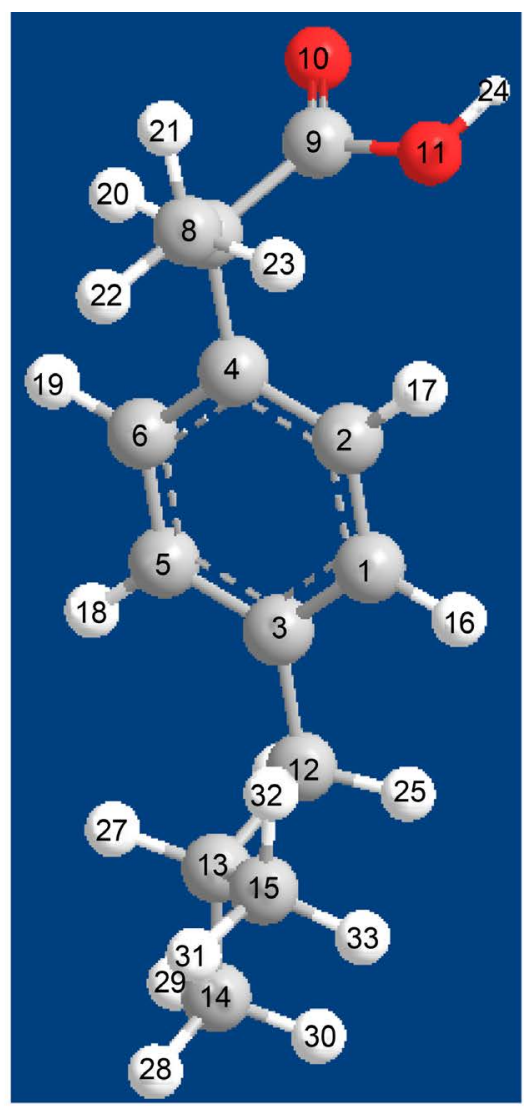

S-FORM

Figure 1. Minimum energy structures of ibuprofen isomers. 
To give more information about cancer, it is mutual electron transfer between the nucleic acid bases and electron acceptor, i.e. free radicals, drugs even some food like grills and fries. Losing an electron from the nucleic acid bases inside the nucleus produces carcinogenic cell in which the nucleus acts as electron donor to any electron acceptor such as in case of Paracetamol metabolite in the liver, NABQI, Figure 2, which has high electron affinity being sufficient to withdraw an electron from guanine of the lowest Ip energy among all the other nucleic acid bases, Table 2, in the liver cell nucleus in absence of glutathione [13]. Therefore the nucleus lacks an electron to produce cationic nucleus as a free radical producing cancerous cell. In the cancerous cells, guanine is in its cationic form. This cancer can be treated by drugs having the spontaneity of electron donor to compensate the electron deficiency from the nucleus such as ibuprofen drug anions. From comparison point of view with respect to the nucleic acid bases it has been found the following values of the total energy, ionization energy, Ip and electron affinity, Ea, in Table 2.

From Table 2, it has been found that guanine molecule has the lowest Ip, 6.1879 among all the other nucleic acid bases hence it acts as an electron donor forming the

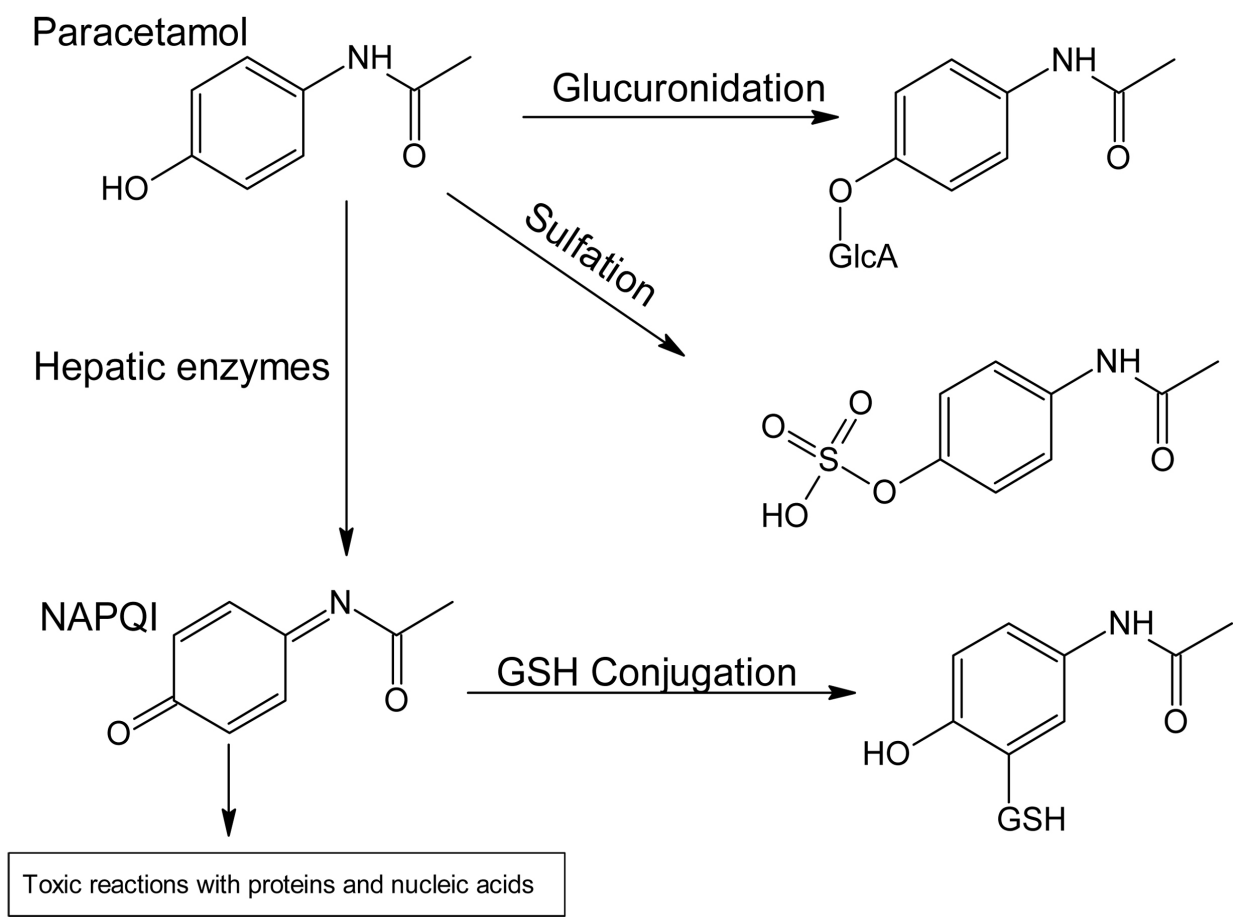

Figure 2. Three path ways of paracetamol metabolism in liver.

Table 1. Comparative DFT-6-31**G parameters of Ibuprofen isomers [15].

\begin{tabular}{cccc}
\hline Compound & TE au & $\mathrm{Ip} \mathrm{eV}$ & Ea eV \\
\hline S-IBF & -656.5408 & 6.6837 & 0.8879 \\
R-IBF & -656.5419 & 6.6766 & 0.9048 \\
\hline
\end{tabular}

N.B. Ip is the ionization potential energy and Ea is the electron affinity. 
Table 2. DFT/6-31G ${ }^{\star *}$ parameters of Nucleic Acid Bases (NAB) and IBF drug in gas phase.

\begin{tabular}{cccc}
\hline Compound & TE au & Ip eV & Ea eV \\
\hline Adenine & -467.17488 & 6.4061 & +1.2672 \\
Guanine & -542.37704 & 6.1879 & +1.2828 \\
Guanine cation & -542.06199 & 11.91478 & +6.5582 \\
Cytosine & -394.82291 & 6.5819 & +1.4768 \\
Uracil & -414.70313 & 7.3316 & +1.8626 \\
S-ibuprofen in the stomach & -656.5408 & 6.6837 & +0.8879 \\
S-ibuprofen in the small intestine & -655.9788 & 0.9015 & -1.4392 \\
\hline
\end{tabular}

cationic guanine, in the cancerous cell, which has high electron affinity being equal to $6.5582 \mathrm{eV}$. In our calculations the guanine cation represents the cancerous cell in this work. Guanine cation in the cancerous cells has high ionization potential energy in water, $7.8293 \mathrm{eV}$ and relatively high electron affinity in water, $2.5486 \mathrm{eV}$, Table 6 . Therefore the guanine cation has good stability in the human being as cancer; hence the definition of cancer is the electron deficiency in guanine cation in the nuclei of the cancerous cell. Therefore in our calculations, guanine cation represents the cancerous cell.

From the DFT calculations, the high electron affinity of guanine cation in the carcinogenic cell is equal to $6.5582 \mathrm{eV}$ and the heat content change from guanine to guanine cation equals $197.276 \mathrm{k} \mathrm{cal} \mathrm{mol}^{-1}$. The condition of treatment of cancer by drug anions can be illustrated as follows:

$$
\begin{gathered}
{\left[\left(\mathrm{Ip}_{(\text {IBF anion })}-\mathrm{C}^{-}\right)-\left(\mathrm{Ea}_{(\text {guan cation })}+\mathrm{C}^{+}\right)\right] \leq 0} \\
\text { Eet }=\mathrm{Ip}_{\text {anion }}-\mathrm{Ea}_{(\text {guanine cation })}-\left(\mathrm{C}^{+}+\mathrm{C}^{-}\right) \\
\text {Eet }=0.9015-6.5582-\left(\mathrm{C}^{+}+\mathrm{C}^{-}\right)=-6.08613 \mathrm{eV} \\
\text { Eet }=\left(\mathrm{Ip}_{\text {anion }}-\mathrm{C}^{-}\right)-\left(\mathrm{Ea}_{\text {guanine cation }}+\mathrm{C}^{+}\right) \\
(0.9015-0.37867)-(6.5582+0.050764)=-6.08613 \mathrm{eV}
\end{gathered}
$$

where Eet is the electron transfer energy, Ip is the ionization potential energy of the IBF-anions as a donor, $\mathrm{C}^{-}$is the columbic potential energy of anions , $\mathrm{Ea}$ is the electron affinity of the guanine cation as an acceptor and $\mathrm{C}^{+}$is the columbic potential energy of guanine cation in the gas phase using DFT $-6-31^{\star *} \mathrm{G}$ calculations.

$\mathrm{Ip}_{\text {(IBF anion) }}(0.9015 \mathrm{eV})$ and $\mathrm{Ea}_{\text {(guanine cation) }}$ is the electron affinity of guanine cation being equal to $6.5582 \mathrm{eV}$, Table 2, then the electron transfer energy equals to $-6.08613 \mathrm{eV}$ taking in our consideration the columbic potential energies of the IBF anion and guanine cation. The negative sign of the electron transfer energy means that the electrons come spontaneously from the mixture of IBF anions and the conjugate IBF molecules to guanine cations strongly, hence the strong spontaneity of the electron transfer from the IBF anions to the cationic guanine in the carcinogenic cell in the intestine and blood gives the chance to inhibit different types of cancers as colon, protostate, lung and breast cancers, [2] [3] [4]. The calculations of the $\mathrm{S}$ and $\mathrm{R}$ forms are consistent and it is enough to do the calculations with one of them which is S-form, moreover, it has 
been concluded that the bioactive isomer of IBF is the S-form as reported by Naveen Chhabra et al. [6].

\subsection{Breast Cancer Treatment}

Matthew Gdovin and others have found out an experimental method to kill the cancer cells in two hour by injection of ethanolic solution of nitrobenzaldehyde and stay sometimes to let the solution diffuses in the breast tumor and then aim uv-light on the tumor for about two hours causing the cancerous cells become very acidic inside then the breast tumor disappears because the carcinogenic cells commit suicide in the strong acidic medium as explained by Gdovin group [12]. So the ethanolic solution of derivatives para, meta and ortho of nitrobenzaldehyde have been studied by time dependent TD-DFT/6-31 ${ }^{* *}$ G calculations [15] to study the excited states in these molecules.

After the incidence of the uv-light on the ethanolic solution of nitrobenzaldehyde, the molecules promote from the ground state to the excited states. From the previous Tables 3-5 it can be concluded that nitrobenzaldehydes have low ionization potential energies in their excited states and regarding the high electron affinity of cationic guanine, in ethanolic solution equals to $2.676513 \mathrm{eV}$, Table 6, in the cancerous cells, then the electron transfer energy has negative sign which means that the electron transfer spontaneity from the excited molecules of nitrobenzaldehydes to the cationic guanine in the cancerous cells takes place strongly as has been concluded with IBF anions to compensate the electron deficiency in the cationic guanine of the cancerous cells.

From Table 3, the oscillator strength of the transition to the second excited state in the para derivative has a value, 0.0357 hence the electronic transition to this excited state is allowed, hence the TD-DFT-calculated ionization potential energy in this excited state has low value being equal to $1.576936 \mathrm{eV}$. Taking in our consideration the columbic potential energies of guanine cation in ethanol and $\mathrm{P}-\mathrm{NO}_{2}$ benzaldehyde in the excited state, in ethanolic solution, in addition to the low ionization potential energy of $\mathrm{P}-\mathrm{NO}_{2}$ benzaldehyde in the second excited state and the electron affinity of guanine cation in ethanol, $2.676513 \mathrm{eV}$, Table 6, therefore the excited molecules can contribute to the electron transfer to guanine cations in the cancerous cells due to the

Table 3. TD-DFT excitation energies and oscillator strengths of ethanolic solution of $\mathrm{P}-\mathrm{NO}_{2}$ benzaldehyde.

\begin{tabular}{|c|c|c|c|c|c|c|}
\hline $\begin{array}{c}\text { Excited state } \\
\text { singlet-A }\end{array}$ & Eigenvectors & Transition & $\Delta \mathrm{E} \mathrm{eV}$ & $\lambda_{\text {calc. }} \mathrm{nm}$ & $\mathrm{F}$ & Ex Ip eV \\
\hline \multicolumn{7}{|c|}{ Excited State 1} \\
\hline $\begin{array}{l}39->40 \\
39->41\end{array}$ & $\begin{array}{c}0.63499 \\
-0.26192\end{array}$ & $\begin{array}{l}\psi_{\mathrm{m}}->\psi_{\mathrm{m}+1} \\
\psi_{\mathrm{m}}->\psi_{\mathrm{m}+2}\end{array}$ & 3.3025 & 375.43 & 0.0000 & 1.533128 \\
\hline \multicolumn{7}{|c|}{ Excited State 2} \\
\hline $\begin{array}{l}37->42 \\
38->40\end{array}$ & $\begin{array}{l}0.14475 \\
0.67061\end{array}$ & $\psi_{\mathrm{m}-2}->\psi_{\mathrm{m}+3}$ & 3.8179 & 324.74 & 0.0357 & 1.576936 \\
\hline \multicolumn{7}{|c|}{ Excited State 3} \\
\hline $\begin{array}{l}36->40 \\
36->41\end{array}$ & $\begin{array}{l}0.65583 \\
0.20150\end{array}$ & $\begin{array}{l}\psi_{\mathrm{m}-3}->\psi_{\mathrm{m}+1} \\
\psi_{\mathrm{m}-3}->\psi_{\mathrm{m}+2}\end{array}$ & 3.8198 & 324.58 & 0.0000 & 1.569131 \\
\hline
\end{tabular}


Table 4. TD-DFT excitation energies and oscillator strengths of ethanolic solution of m-nitrobenzaldehyde.

\begin{tabular}{|c|c|c|c|c|c|c|}
\hline $\begin{array}{c}\text { Excited state } \\
\text { singlet-A }\end{array}$ & Eigenvectors & Transition & $\Delta \mathrm{E} \mathrm{eV}$ & $\lambda_{\text {calc. }} \mathrm{nm}$ & $\mathrm{f}$ & Ex Ip eV \\
\hline \multicolumn{7}{|c|}{ Excited state 1} \\
\hline $\begin{array}{l}39->40 \\
39->41\end{array}$ & $\begin{array}{c}-0.38190 \\
0.56353\end{array}$ & $\begin{array}{l}\psi_{\mathrm{m}}->\psi_{\mathrm{m}+1} \\
\psi_{\mathrm{m}}->\psi_{\mathrm{m}+2}\end{array}$ & 3.6203 & 342.47 & \multirow[t]{2}{*}{0.0001} & \multirow[t]{2}{*}{1.264399} \\
\hline \multicolumn{5}{|c|}{ Excited state 2} & & \\
\hline $36->40$ & 0.63656 & $\psi_{\mathrm{m}-3}->\psi_{\mathrm{m}+1}$ & \multirow{4}{*}{3.9108} & \multirow{5}{*}{342.47} & \multirow{5}{*}{0.0001} & \multirow{4}{*}{1.464898} \\
\hline $36->41$ & 0.13159 & $\psi_{\mathrm{m}-3}->\psi_{\mathrm{m}+2}$ & & & & \\
\hline $39->40$ & 0.15913 & $\psi_{\mathrm{m}}->\psi_{\mathrm{m}+1}$ & & & & \\
\hline $39->41$ & 0.13339 & $\psi_{\mathrm{m}}->\psi_{\mathrm{m}+2}$ & & & & \\
\hline \multicolumn{5}{|c|}{ Excited state 3} & & \\
\hline $36->40$ & -0.19827 & $\psi_{\mathrm{m}-3}->\psi_{\mathrm{m}+1}$ & & & & \\
\hline $39->40$ & 0.56276 & $\psi_{\mathrm{m}}->\psi_{\mathrm{m}+1}$ & 4.0769 & 304.11 & 0.0000 & 1.44943 \\
\hline $39->41$ & 0.35182 & $\psi_{\mathrm{m}}->\psi_{\mathrm{m}+2}$ & & & & \\
\hline
\end{tabular}

Table 5. TD-DFT excitation energies and oscillator strengths of ethanolic solution of o-nitrobenzaldehyde.

\begin{tabular}{|c|c|c|c|c|c|c|}
\hline $\begin{array}{c}\text { Excited state } \\
\text { singlet-A }\end{array}$ & Eigenvectors & Transition & $\Delta \mathrm{E} \mathrm{eV}$ & $\lambda_{\text {calc. }} \mathrm{nm}$ & $\mathrm{f}$ & Ex Ip eV \\
\hline \multicolumn{7}{|c|}{ Excited state 1} \\
\hline $\begin{array}{l}39->40 \\
39->41\end{array}$ & $\begin{array}{c}0.65966 \\
-0.16240\end{array}$ & $\begin{array}{l}\psi_{\mathrm{m}}->\psi_{\mathrm{m}+1} \\
\psi_{\mathrm{m}}->\psi_{\mathrm{m}+2}\end{array}$ & 3.0039 & \multirow[t]{2}{*}{412.75} & \multirow[t]{2}{*}{0.0000} & \multirow[t]{2}{*}{1.5717400} \\
\hline \multicolumn{4}{|c|}{ Excited state 2} & & & \\
\hline $36->40$ & 0.57540 & $\psi_{\mathrm{m}-3}->\psi_{\mathrm{m}+1}$ & \multirow{3}{*}{3.7879} & \multirow{4}{*}{327.32} & \multirow{4}{*}{0.0000} & \multirow{4}{*}{1.4422677} \\
\hline $36->41$ & 0.10679 & $\psi_{\mathrm{m}-3}->\psi_{\mathrm{m}+2}$ & & & & \\
\hline $39->41$ & -0.34330 & $\psi_{\mathrm{m}}->\psi_{\mathrm{m}+2}$ & & & & \\
\hline \multicolumn{4}{|c|}{ Excited state 3} & & & \\
\hline $\begin{array}{l}37->41 \\
38->40\end{array}$ & $\begin{array}{c}-0.15258 \\
0.66388\end{array}$ & $\begin{array}{c}\psi_{\mathrm{m}-2}->\psi_{\mathrm{m}+1} \\
\psi_{\mathrm{m}-1}->\psi_{\mathrm{m}}\end{array}$ & 3.7946 & 326.74 & 0.0757 & 1.5841700 \\
\hline
\end{tabular}

Table 6. DFT-6-31** G parameters of guanine cation in different solvents.

\begin{tabular}{cccc}
\hline Solvent & TE au & Ip eV & Ea eV \\
\hline Ethanol & -542.189198 & 7.959607 & 2.676513 \\
Diethyl ether & -542.166122 & 8.750642 & 3.447684 \\
Water & -542.193720 & 7.829264 & 2.548620 \\
Gas & -542.079515 & 11.91478 & 6.558219 \\
\hline
\end{tabular}

negative sign of the electron transfer energy, $-3.620429 \mathrm{eV}$, which means the spontaneity of the electron transfer from the second excited state of p-nitrobenzaldehyde to guanine cation in ethanolic solution as calculated below: 


$$
\begin{aligned}
\text { Eet } & =\mathrm{Ip}_{\left(\mathrm{p}-\mathrm{NO}_{2}-\mathrm{Ben}\right)}-\mathrm{Ea}_{(\text {guan-cat })}-\left(\mathrm{C}+\mathrm{C}^{+}\right) \\
& =1.576936-2.676513-(0.251462+2.276939) \\
& =-3.620429 \mathrm{eV}
\end{aligned}
$$

Therefore the negative sign of the electron transfer energy, Eet, indicates to the spontaneity of the electron transfer from ethanolic solution of p-nitrobenzaldehyde to guanine cation to compensate the electron deficiency in guanine cation in the cancerous cells in presence of uv-light (325 nm).

From the previous Table 4, it can be concluded that the zero oscillator strengths of all the electronic transitions of the meta derivative of nitrobenzaldehyde mean that all the electronic transitions to the excited states are forbidden in the meta derivative molecule.

From Table 5, it can be noticed that the electronic transition to the third excited state of the ortho derivative lies at $327 \mathrm{~nm}$ and it has appreciable oscillator strength value, 0.0757 therefore the electronic transition to the third excited state of the ortho derivative is allowed. Hence the ortho nitro derivative is the main suitable derivative for this experiment of Gdovin group. It has been found that the calculated electron transfer energy from the allowed transition of the third excited state to the cationic guanine in the cancerous cell has the value $-3.573808 \mathrm{eV}$ indicating to the spontaneous electron transfer from the third excited state of the ortho derivative in presence of uv-irradiation in ethanolic solution to compensate the electron deficiency in the cationic guanine in the cancerous cells rendering them to be normal.

$$
\begin{aligned}
\text { Eet } & =\mathrm{Ip}_{\left(\mathrm{o}-\mathrm{NO}_{2} \text { Benz }\right)}-\mathrm{Ea}_{(\text {guan-cat })}-\left(\mathrm{C}+\mathrm{C}^{+}\right) \\
& =1.58417-2.676513-(0.204526+2.276939) \\
& =-3.573808 \mathrm{eV}
\end{aligned}
$$

Therefore, ethanolic solution of o-nitrobenzaldehyde compensates the electron deficiency of guanine cation in presence of uv-irradiation at $\lambda=327 \mathrm{~nm}$.

It is important to indicate to diethyl ether as solvent instead of ethanol in ethanolic solution of nitrobenzaldehyde and it is better because the electron affinity of guanine cation in diethyl ether is higher than in case of ethyl alcohol, Table 6. Of course the uvwavelengths with which the electron transfer takes place, should be calculated in case of diethyl ether as solvent. The negative electron transfer energy will be lower value than in case of using ethyl alcohol as solvent, hence the spontaneity of the electron transfer to guanine cation will be stronger and the cancer treatment will be easier in case of using diethyl ether as solvent than in case of using ethanolic solution of nitrobenzaldehydes.

Ethanol is the solvent in the injected solution of nitrobenzaldehyde in the breast tumor and it is metabolized to acetaldehyde by alcohol dehydrogenase $(\mathrm{ADH})$ enzyme. The aldehyde dehydrogenase enzyme (ALDH) is responsible for oxidation of acetaldehyde to acetic acid. The degradation of acetaldehyde depends on the activity of this enzyme. The total Alcohol dehydrogenase activity is significantly higher in cancer tissues than in these healthy organs (e.g. liver, stomach, esophagus, colorectum). The activity of $\mathrm{ADH}$ is much higher than the activity of ALDH. The cancer cells have a greater capability for ethanol oxidation but less ability to remove hydrogen from acetaldehyde 
than in normal tissues. In addition, significant differences of ADH isoenzymes activities between cancer tissues and healthy organs may be a factor intensifying carcinogenesis by the increased ability to acetaldehyde formation from ethanol and disorders in metabolism of some biologically important substances (e.g. retinoic acid). The changes in activity of particular ADH isoenzymes in the sera of patients with different cancers, seemed to be caused by release of these isoenzymes from cancer cells, and may be useful for diagnostics of this cancer. The particular isoenzymes of $\mathrm{ADH}$ present in the serum may indicate to the cancer localization [11]. But if this assumption of losing the protons from nitrobenzaldehyde and ethyl alcohol to render the cancerous cells very acidic and commit suicide this means that the wine drink can cure cancer and of course this isn't the reality.

It is important to know the effect of the uv-light on ethanol itself as solvent. Of course the ethanol molecules promote to the excited states in presence of the uv-light depending on the wavelength as shown below:

From Table 7, it can be concluded that the ionization of the third excited state of ethyl alcohol takes place in presence of short uv light at $\lambda=169 \mathrm{~nm}$ which is far from the uv-wavelengths of the excitation of ethanolic solution of nitrobenzaldehyde, 325 $327 \mathrm{~nm}$. Hence, the ethanol molecules don't contribute in the electron transfer to the guanine cation in the cancerous cells in the uv region 325, $327 \mathrm{~nm}$. However the alteration of ethanol to acetaldehyde due to $\mathrm{ADH}$ enzyme [11] has the heat content change being equal to $760.335 \mathrm{k} \mathrm{cal} \mathrm{mol}^{-1}$ this means how much effort done by the $\mathrm{ADH}$ enzyme. Dealing with the ionization constant of ethanol molecule, it is not much different from water and it is necessary to take in our consideration the TD-DFT charge densities of the ethanol molecule, Table 8, as follows:

It can be noticed from the previous values of ethanol charge densities that the hydrogen atom attached with the hydroxyl oxygen atom has the highest positive charge, 0.513135 , Table 8 and the acidity of ethanol is nearly the same as that of water as indicated by their pKa being ranged between $15.7-16$. This means that the ratio between its anions and its molecular forms is very low even at blood $\mathrm{pH}=7.4$, therefore the loss of protons from ethanol molecule is weak possibility except by the aid of ADH enzyme

Table 7. TD-DFT excitation energies and oscillator strengths of ethyl alcohol.

\begin{tabular}{|c|c|c|c|c|c|c|}
\hline $\begin{array}{c}\text { Excited state } \\
\text { singlet-A }\end{array}$ & Eigenvectors & Transition & $\Delta \mathrm{E} \mathrm{eV}$ & $\lambda_{\text {calc. }} \mathrm{nm}$ & $\mathrm{f}$ & Ex Ip eV \\
\hline \multicolumn{7}{|c|}{ Excited state 1} \\
\hline $\begin{array}{l}13->14 \\
13->15\end{array}$ & $\begin{array}{c}0.67973 \\
-0.17057\end{array}$ & $\begin{array}{l}\psi_{\mathrm{m}}->\psi_{\mathrm{m}+1} \\
\psi_{\mathrm{m}}->\psi_{\mathrm{m}+2}\end{array}$ & 6.3756 & \multirow[t]{2}{*}{194.47} & \multirow[t]{2}{*}{0.0002} & \multirow[t]{2}{*}{0.108383} \\
\hline \multicolumn{4}{|c|}{ Excited state 2} & & & \\
\hline $13->14$ & 0.18000 & $\psi_{\mathrm{m}}->\psi_{\mathrm{m}+1}$ & \multirow{3}{*}{7.0224} & \multirow{3}{*}{176.56} & \multirow{3}{*}{0.0005} & \multirow{3}{*}{0.201893} \\
\hline $13->15$ & 0.65734 & $\psi_{\mathrm{m}}->\psi_{\mathrm{m}+2}$ & & & & \\
\hline $13->16$ & 0.14683 & $\psi_{\mathrm{m}}->\psi_{\mathrm{m}+3}$ & & & & \\
\hline \multicolumn{7}{|c|}{ Excited state 3} \\
\hline $\begin{array}{l}13->14 \\
13->15\end{array}$ & $\begin{array}{c}-0.16170 \\
0.68251\end{array}$ & $\begin{array}{c}\psi_{\mathrm{m}}->\psi_{\mathrm{m}+1} \\
\psi_{\mathrm{m}-}->\psi_{\mathrm{m}+2}\end{array}$ & 7.3207 & 169.36 & 0.0495 & 0.178419 \\
\hline
\end{tabular}


in cancerous cells which performs much effort to do, as reported by Wojciech [11] .

So, the cure of breast cancer tumor by Matthew Gdovin [12] is due to the electron transfer from the second and third excited states of para and ortho derivatives of nitrobenzaldehyde to the cationic guanine in the cancerous cells which may be enhanced by the proton production from ethyl alcohol and its main metabolite acetaldehyde by the enzymes ALDH whose activity is much lower than ADH enzymes [11], Figure 3. Therefore, it can be suggested that the electron transfer is much preferred than proton transfer in the cure of breast cancer the most aggressive types of cancer and one of the hardest to treat. The production of protons from ethyl alcohol alteration to its anion as metastable state, Figure 4, has enthalpy value of $317.340 \mathrm{k} \mathrm{cal} \mathrm{mol}^{-1}$ which corresponds to $13.774241 \mathrm{eV}$ per ethyl alcohol molecule. The production of protons from ethyl alcohol may be performed by the aid of ADH enzyme as has been suggested by Gdovin [12] and Wojciech [11].

Table 8. TD-DFT charge densities of ethanol.

\begin{tabular}{ccc}
\hline No. & Atom & Charge density \\
\hline 1 & $\mathrm{C}$ & -0.666689 \\
2 & $\mathrm{C}$ & -0.239419 \\
3 & $\mathrm{O}$ & -0.660615 \\
4 & $H$ & 0.193943 \\
5 & $\mathrm{H}$ & 0.220397 \\
6 & $\mathrm{H}$ & 0.220457 \\
7 & $\mathrm{H}$ & 0.209422 \\
8 & $\mathrm{H}$ & 0.209369 \\
$9 \mathrm{OH}$ & $\mathrm{H}$ & 0.513135 \\
\hline
\end{tabular}
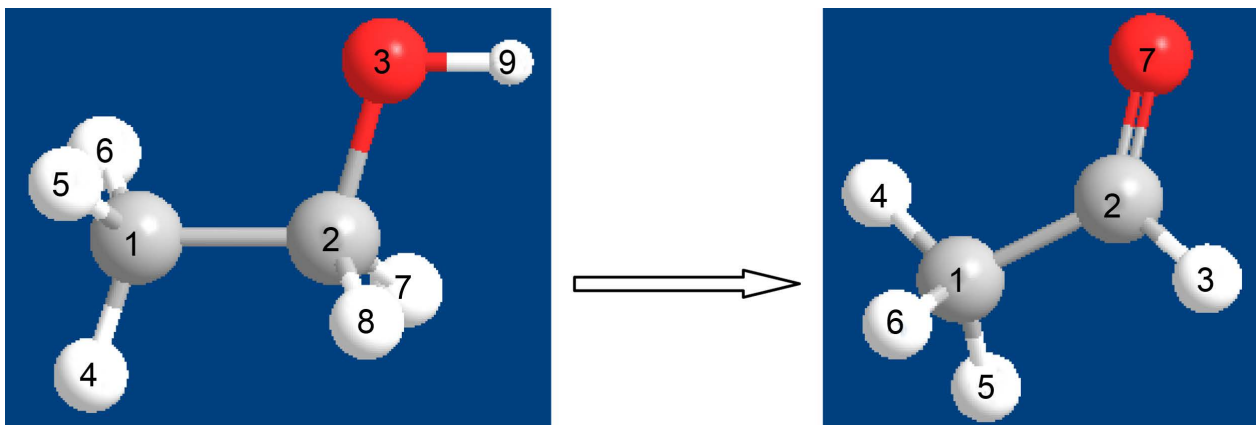

Figure 3. Production of protons via alteration of ethyl alcohol molecule to acetaldehyde.
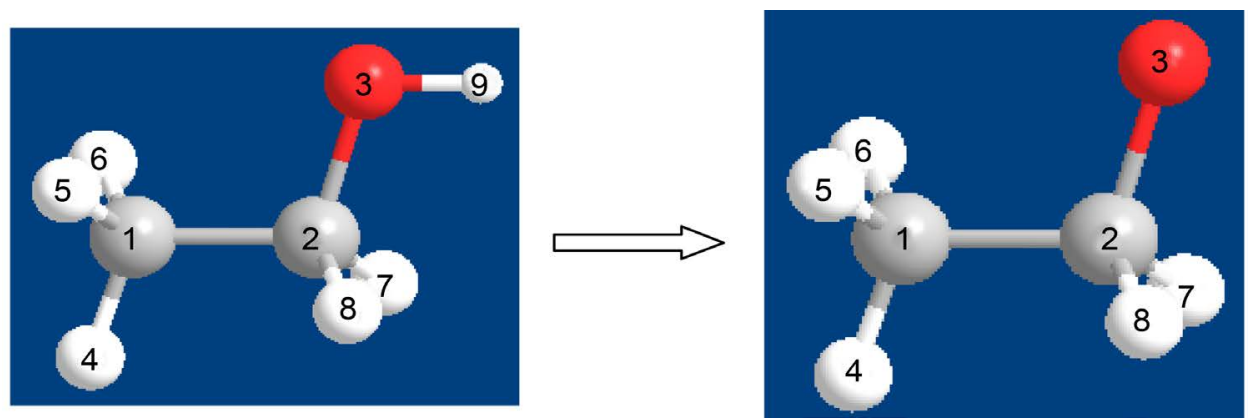

Figure 4. Production of proton from ethyl alcohol molecule via alteration to its anion as metastable state. 


\section{Conclusions}

1) It is good for the health to take ibuprofen drug regularly to avoid cancers of gastrointestine, protostate, breast and lung and from general point of view, it is better to use the carboxylic acid drugs for the cancer treatment.

2) The electron transfer from ethanolic solution of nitrobenzaldehydes to cancerous cells in presence of uv-irradiation is the real cause in the treatment of breast cancer in two hours by Matthew Gdovin group rendering the cancerous cells to be normal rendering the cancerous cells to be normal and there is not suicide of the cancerous cells.

\section{References}

[1] Torre, L.A., Bray, F., Siegel, R.L., Ferlay, J., Lortet-Tieulent, J. and Jemal, A. (2015) Global Cancer Statistics, 2012. CA: A Cancer Journal for Clinicians, 65, 87-108. https://doi.org/10.3322/caac.21262

[2] Akrami, H., Aminzadeh, S., and Fallahi, H. (2014) Inhibitory Effect of Ibuprofen on Tumor Survival and Angiogenesis in Gastric Cancer cell. Tumor Biology, 1-7.

[3] Harris, R.E., Beebe-Donk, J., Doss, H. and Burr Doss, D. (2005) Aspirin, Ibuprofen, and Other Non-Steroidal Anti-Inflammatory Drugs in Cancer Prevention: A Critical Review of Non-Selective COX-2 Blockade (Review). Oncology Reports, 13, 559-583.

[4] Harris, R.E., Beebe-Donk, J. and Alshafie, G.A. (2007) Reduced Risk of Human Lung Cancer by Selective Cyclooxygenase 2 (Cox-2) Blockade: Results of a Case Control Study. International Journal of Biological Sciences, 3, 328-334. https://doi.org/10.7150/ijbs.3.328

[5] Hanlon, G., Kooloobandi, A. and Hutt, A. (1994) Microbial Metabolism of 2-Arylpropanoic Acids: Effect of Environment on the Metabolism of Ibuprofen by Verticillium lecanii. Journal of Applied Bacteriology, 76, 442-447. https://doi.org/10.1111/j.1365-2672.1994.tb01100.x

[6] Chhabra, Na., Aseri, M.L. and Padmanabhan, D. (2013) Ibuprofen Isomers: A Review of Drug Isomerism and Its Significance. International Journal of Applied and Basic Medical Research, 3, 16-18

[7] Carey, L., Winer, E., Viale, G., Cameron, D. and Gianni, L. (2010) Triple-Negative Breast Cancer: Disease Entity or Title of Convenience. Nature Reviews Clinical Oncology, 7, 683692. https://doi.org/10.1038/nrclinonc.2010.154

[8] Mego, M., Mani, S.A. and Cristofanilli, M. (2010) Molecular Mechanisms of Metastasis in Breast Cancer-Clinical Applications. Nature Reviews Clinical Oncology, 7, 693-701. https://doi.org/10.1038/nrclinonc.2010.171

[9] Narod, S.A. (2010) BRCA Mutations in the Management of Breast Cancer: The State of the Art. Nature Reviews Clinical Oncology, 7, 702-707. https://doi.org/10.1038/nrclinonc.2010.166

[10] Rehman, F.L., Lord, C.J. and Ashworth, A. (2010) Synthetic Lethal Approaches to Breast Cancer Therapy. Nature Reviews Clinical Oncology, 7, 718-724. https://doi.org/10.1038/nrclinonc.2010.172

[11] Jelski, W. and Szmitkowski, M. (2008) Alcohol Dehydrogenase (ADH) and Aldehyde Dehydrogenase (ALDH) in the Cancer Diseases. Clinica Chimica Acta, 395, 1-5. https://doi.org/10.1016/j.cca.2008.05.001

[12] Kadri, N.B., Gdovin, M., Alyassin, N., Avila, J., Cruz, A., Cruz, L., Holliday, S., Jordan, Z., Ruiz, C. and Watts, J. (2016) Photodynamic Acidification Therapy to Reduce Triple Negative Breast Cancer Growth in Vivo. Journal of Clinical Oncology, ASCO Annual Meeting, 34, e12574. 
[13] El-Shahawy, A. (2014) DFT Cancer Energy Barrier and Spectral Studies of Aspirin, Paracetamol and Some Analogues. Computational Chemistry, 2, 6-17.

https://doi.org/10.4236/cc.2014.21002

[14] El-Shahawy, A. (2011) Computational DFT/CI Spectroscopic Structural Studies of Some Complexes of Benzalbarbituric Acid. Journal of Molecular Structure, 987, 232-240. https://doi.org/10.1016/j.molstruc.2010.12.030

[15] El-Shahawy, A., Gashlan, H., Qusti, S., Ezzat, G. and Emara, H. (2016) DFT-Quantum Spectroscopic Studies and Anti-Cancer Effect of Ibuprofen Drug and Some Analogues. Computational Chemistry, 4, 33-50. https://doi.org/10.4236/cc.2016.42004

Submit or recommend next manuscript to SCIRP and we will provide best service for you:

Accepting pre-submission inquiries through Email, Facebook, LinkedIn, Twitter, etc. A wide selection of journals (inclusive of 9 subjects, more than 200 journals)

Providing 24-hour high-quality service

User-friendly online submission system

Fair and swift peer-review system

Efficient typesetting and proofreading procedure

Display of the result of downloads and visits, as well as the number of cited articles Maximum dissemination of your research work

Submit your manuscript at: http://papersubmission.scirp.org/

Or contactcc@scirp.org 